Worker Preferences, Sorting and Aggregate Patterns of Health Insurance Coverage

\author{
Richard A. Hirth, Ph.D.* \\ Reagan Baughman, Ph.D. \\ Michael E. Chernew, Ph.D. \\ Emily C. Shelton, B.A.
}

University of Michigan, Department of Health Management and Policy (RAH, MEC, ECS) University of New Hampshire, Department of Economics (RB)

\author{
Contact Information: \\ Richard A. Hirth, Ph.D. \\ Department of Health Management and Policy \\ University of Michigan, School of Public Health \\ 109 S. Observatory \\ Ann Arbor, MI 48109-2029 \\ Phone: (734)936-1306 \\ Fax: (734)764-4338 \\ Email: rhirth@umich.edu
}

February 9, 2006

\begin{abstract}
*This work was supported by a grant from the Economic Reseach Initiative on the Uninsured (ERIU) at the University of Michigan, funded by the Robert Wood Johnson Foundation. We thank Roger Feldman, Tom DeLeire, and seminar participants at the ERIU 2005 Annual Research Conference, the 2005 AcademyHealth Annual Research Meeting, and Carleton College for helpful comments.
\end{abstract}




\title{
Worker Preferences, Sorting and Aggregate Patterns of Health Insurance Coverage
}

\begin{abstract}
To assess the performance of the employment-based health insurance system, it is necessary to understand how well workers sort into jobs that offer their desired mix of cash wages relative to benefits. However, few studies directly measure the extent of sorting. We quantify the prevalence of mismatches between workers’ preferences and firms’ insurance offerings by considering two types of mismatch: 1) workers who appear to desire coverage through their employer, but work for firms that do not offer coverage, and; 2) workers who appear not to desire coverage through their employer, but work for firms that offer coverage. Most workers (79.6 percent) enjoy labor market matches that appear consistent with their preferences. The remaining 20.4 percent of workers appear to be mismatched. For most of these mismatches, the primary consequence is lower wages than would be earned if individuals were better matched in the labor market. However, a minority of the identified mismatches appear to be "involuntarily uninsured" workers who would gain insurance if they were to find a better match. Extrapolating from the analysis sample, these involuntarily uninsured workers and their uninsured dependents may represent up to one in six uninsured individuals in the United States.
\end{abstract}




\section{Background}

The majority of working-age Americans and their families obtain health insurance through employers. In 2002, 64.2 percent of the under-65 population held employer-sponsored health insurance (ESI). Nonetheless, more than 20 million working adults lack insurance. These uninsured workers represent more than one in ten working adults in 38 states and more than one in five working adults in 6 states (SHADAC, 2004).

To assess the performance of the employment-based health insurance system, it is necessary to understand how well workers sort into jobs that offer their desired mix of cash wages relative to benefits. This sorting process can be described by a Tiebout model in which wage and benefit offerings are local public goods to the firm’s workers (Goldstein and Pauly 1976). If perfect sorting occurs each worker would be matched to a firm offering their preferred wage/benefit mix. The set of employers in a market would offer benefit packages consistent with the distribution of worker preferences and the rate of uninsurance among workers would reflect demand for insurance relative to other goods.

The efficiency of sorting is a fundamental issue for health policy and for empirical work on health insurance (Chernew and Hirth 2004). If workers sort perfectly on the basis of their preferences, uninsurance among workers indicates low demand rather than an institutional barrier posed by the employer-based insurance system (Long and Marquis 1993). Thus, efforts to alter employer behavior to increase coverage rates would generate welfare losses by forcing workers to pay for coverage they do not desire, as opposed to alleviating welfare losses by giving workers access to a product they desire but were not offered. Conversely, if sorting is imperfect, the firm's behavior and internal decision-making rules become salient to understanding health insurance coverage patterns. 
Labor market sorting also has implications for the design of empirical studies of firmlevel demand for insurance. With perfect sorting, firm characteristics reflect endogenous worker preferences. Thus, studies relying on firm-level variables for identification are subject to the critique that the results are confounded by unobserved worker preferences correlated with firm traits because of worker sorting (e.g., Feldman et al. 1997; Hadley and Reschovsky 2002, Chernew, Frick and McLaughlin 1997). For example, if small employers find it more costly to provide coverage, they would choose to occupy the niche of hiring workers who prefer cash compensation to health insurance.

For several reasons, workers might fail to sort perfectly. To satisfy heterogeneous preferences, perfect sorting requires a large number of firms willing to employ any type of worker. This would not be the case if geographic barriers and firms' needs for specific types of workers limit workers' access to jobs offering their ideal wage/benefit tradeoff. Moreover, offering multiple health plans entails fixed costs to employers, limiting firms' ability to match all workers' preferences exactly (Moran, Chernew, and Hirth 2001). Finally, sorting becomes more complex in a dynamic context. Over time, workers develop firm-specific skills which may limit job mobility; however, their health status or tastes for coverage may also change, generating a mismatch.

Sorting can also occur within firms, with some workers purchasing coverage and others not, but this would require incentives such as copremiums (charging workers a portion of the premium) or targeted wage offsets. Tax laws encourage low copremiums, and wage offsets targeting individuals (as opposed to groups) seem implausible and their existence has rarely been verified despite many attempts (see Blumberg and Nichols 2004 for a review). The lack of full, person-specific wage offsets provides low insurance demanders a strong incentive to sort into 
firms that do not offer coverage. Even firms paying cash "opt outs" to employees who decline coverage generally offer considerably less than the employer premium contribution and often restrict payments to workers with coverage from another source.

Several studies present descriptive statistics or reduced-form estimates consistent with the existence of some degree of sorting. For example, workers in firms that do not offer coverage are more likely to have characteristics associated with low insurance demand-namely, workers who are young, male, or have other sources of insurance (Long and Marquis 1993; McLaughlin and Zellers 1992). McLaughlin and Zellers further report that nearly half of small employers who did not offer coverage claimed a lack of demand on the part of their workers. However, Gruber and Lettau (2000) concluded that the preferences of workers with the highest tax rate appear to receive special weight in firms' decisions, whereas under perfect sorting, all workers' preferences would be reflected in insurance decisions.

The "job lock" literature also indirectly addresses sorting imperfections. This research investigates the hypothesis that people with insurance through their employer are discouraged from switching jobs because they fear losing coverage. If individuals could perfectly sort, there would be no job lock. Currie and Madrian (1999) reviewed this literature, concluding that there is conflicting evidence of job lock.

Few studies directly measure the extent of sorting. Monheit and Vistnes (1999) examine job choice as a function of preferences for insurance. They find that 79 percent of workers who assign a high value to health insurance work for firms that offer coverage, compared to 71 percent of workers who do not think they need insurance at all. This suggests that some sorting occurs but that there are a substantial number of “mismatches” between workers' stated preferences and employers' offer decisions. Scott, Berger, and Black (1989) show that sorting 
increases as workers' incentives to sort change over time due to changes in marginal tax rates or changes in the importance of benefits.

In this paper, we attempt to quantify the extent of missorting between workers' preferences and firms' insurance offerings and propose several indicators of mismatches in the labor market. These indicators reflect either individuals with characteristics of high insurance demanders working in jobs that do not offer them insurance, or individuals working in jobs where they decline an offer of insurance. By quantifying the prevalence of possible mismatches and their consequences in terms of health insurance coverage, we can draw inferences about the extent to which less than perfect sorting in the labor market might contribute to the observed pattern of insurance coverage in the population and, hence, the extent to which reforms addressing the employer role in health insurance could be expected to change aggregate coverage patterns.

\section{Conceptual framework and methods}

Conceptually, we consider workers to be appropriately matched in the labor market if their desire for ESI (or lack thereof) corresponds to their employer's decision to offer ESI to them. Conversely, workers are considered mismatched if their desire for ESI (or lack thereof) conflicts with their employer's offer decision. This conceptual framework results in the four quadrant classification summarized in Figure 1.

To implement this classification system, we use workers’ ESI/insurance status and other observable characteristics to place them into quadrants. Because this strategy relies heavily on revealed preference arguments based on observations of whether workers are offered coverage and take-up that coverage, it is important to define the appropriate price/benefit combinations to 
use when determining whether or not a worker wants coverage. Presumably all workers would want coverage if it were free. We posit that the appropriate price/benefit combinations to test the efficiency of labor market matching are the set of insurance plans available in the market and their premiums. The 'want coverage' group includes workers for whom there exists a benefit/premium combination in their market that they would purchase through their employer if charged the full premium that the plan would charge. The 'do not want coverage' group includes workers unwilling to buy any insurance plan through their employer at its premium. We recognize that some workers in the 'do not want coverage' category may be willing to purchase plans available in other markets or plans not offered due to insurance market imperfections. We also recognize that some workers in the 'do not want coverage' group may purchase coverage through their employer because the employer subsidizes the premium, even though they would prefer no coverage if they faced the full premium.

Consistent with the lack of evidence of individual-specific wage offsets and evidence that take-up decisions are driven by copremiums (Chernew, Frick and McLaughlin 1997) rather than the total premium (employer contribution plus copremium), we assume that all workers offered ESI suffer some wage reduction, regardless of whether they take up coverage. That is, a worker who declines insurance fails to see a dollar-for-dollar increase in cash earnings. Also note that individuals in our 'do not want coverage' category may in fact have high demand for insurance, but not want it through their employer due to the availability of coverage through a spouse or public program. Finally, we do not address the issue of which plan a worker prefers. Workers who accept coverage through their firms may still suffer some degree of 'mismatch' if their employer fails to offer their preferred plan. These caveats are important for interpreting our 
results, which are intended to provide rough estimates of the number of workers mismatched in the labor market.

To facilitate the assessment of the quality of matching between workers' demand for ESI and their employers' decisions to offer them coverage, we divide workers into seven mutually exclusive groups. Workers offered and eligible for ESI through their own employers are placed into three groups: 1) those who accept the offer from their employer; 2) those who decline the offer from their employer, but obtain group coverage through another private or public source ${ }^{1}$; and 3) those who decline the offer of ESI from their employer and remain uninsured. Workers not offered or not eligible for ESI through their own employers are divided into four groups: 1 ) those who purchase private, non-group health insurance $\left.{ }^{2} ; 2\right)$ those who obtain coverage through another private, group source; 3) those who obtain coverage through a public program; and 4) those who remain uninsured. For each group of workers, we classify them as either labor market “matches” or “mismatches.” Our classification scheme is, of course, an approximation, subject to both Type I and Type II errors. Therefore, for each classification, we describe both the basis for the classification and the potential for misclassification.

To determine the frequency of the first type of mismatch (workers offered ESI they do not want), we classify workers via their observed take-up decision. All workers accepting their employer's offer of insurance are presumed to be properly matched even though it is possible that some might prefer a wage/benefit offer different than the one provided by their employer, or may even prefer to be uninsured if they could receive the full premium as extra cash

\footnotetext{
${ }^{1}$ Few workers who decline ESI are covered by public programs. Therefore, we do not differentiate between decliners who take up alternative private vs. public sources of coverage.

${ }^{2}$ In principle, a worker could decline an offer of ESI and then purchase coverage in the non-group market. Due to the disadvantages of purchasing non-group coverage noted below, this situation almost never occurs in practice and likely indicates a very undesirable offer of coverage. Therefore, we classify these rare cases as being in the same category as the vast majority of non-group policy holders who were not offered ESI.
} 
compensation. Conversely, we define all workers who turn down an offer of ESI as being mismatched. This reflects our assumption that all workers offered coverage suffer a wage loss as a consequence of the insurance offer, relative to what they could have earned in an ideal labor market match that did not offer them insurance that they did not value enough to take up. We divide decliners into those who obtain insurance through another private or public group source and those who remain uninsured. These two types of ESI decliners differ substantially. Workers who decline coverage because it is available through another source are likely to have high demand for insurance even though they apparently have low demand for their own ESI, while workers who decline ESI and remain uninsured apparently have low demand for any coverage, not just for their own ESI. Those declining coverage because they obtain insurance from another source may be misclassified as mismatches if they are willing to sacrifice wages for the option value of access to a redundant source of coverage. Similarly, those declining ESI and remaining uninsured might be misclassified if they place sufficient value on the ability to take up ESI in the future.

Our measure of the second type of mismatch, workers who would like ESI but do not receive an offer, is more complex because a mismatch often cannot be inferred using revealed preference arguments based on observable insurance take up decisions. Instead, it requires an inference about whether a worker not offered coverage would have taken up an offer if it had been made.

One group for whom such an inference can be drawn based on observed behavior is those purchasing non-group coverage. High loading factors, strict medical underwriting, and coverage exclusions are prevalent in the non-group market. Thus, it seems reasonable to infer that employees purchasing non-group coverage would have desired and taken up an offer of ESI and, 
hence, appear mismatched in the labor market. These workers demonstrated high demand for coverage through their willingness to pay the full premium for a plan that is typically expensive and limited relative to ESI. The primary threat to the validity of this classification is that some workers holding non-group coverage may prefer the "portability" of individually owned insurance relative to insurance tied to an employer.

For other workers not offered ESI, we classify them as "high ESI demand mismatches" only if they have traits associated with high demand for insurance and do not obtain insurance through another private source of group coverage or a public program. By defining workers with other group or public coverage as 'low ESI demanders', we take a conservative approach in estimating the extent of the mismatch. Essentially, we assume that because coverage was taken up from another source, the worker would not like to trade an offer of ESI for lower wages. Certainly, some of these workers were mismatched initially, but compensated by obtaining alternative coverage. The alternative coverage may not be as desirable as obtaining ESI through a better match, but at a minimum, these workers were able to avoid most obvious consequence of a mismatch (uninsurance). Thus, the "high ESI demand mismatches" are limited to those with non-group coverage plus those who are uninsured but have characteristics indicating high insurance demand based on a model described below. The types of workers falling into each of the quadrants in our conceptual framework are summarized in Figure 2.

Each of these groups is defined by observed ESI/insurance status except for the division of uninsured workers not offered ESI into high demanders (mismatches) and low demanders (appropriate sorting). To accomplish this division, we infer which of these workers would have desired and taken up an ESI offer based on observable correlates of demand for insurance. These traits were selected based on the literature and included factors related to medical 
needs/expenditures, valuation of insurance, and risk aversion. Self-reported health status is a generally accepted measure of individual demand for health services. We consider an individual to have a preference for insurance if he/she reports fair or poor health, or if any member of his/her family under age 65 reports health as such. Blumberg and Nichols (2001) found that having a family member in poor or fair health increased the likelihood that low income workers enrolled in ESI. Similarly, we treat workers over age 40 and those with children as having a preference for insurance because higher medical expenditures are associated with both age and family size. The extent to which an individual is willing to take risks is also used as a measure of preference for insurance. Risk aversion is not necessarily associated with greater medical expenditure, but indicates a preference for not being at risk for potentially large medical costs. Since health insurance appears to be a normal good, income is also expected to positively influence demand for coverage. Each of these factors is consistent with the Blumberg and Nichols (2004) conceptual model of demand for insurance.

Our approach to identifying demand for insurance uses a probit model to obtain a prediction of the probability of being insured. Because some households have more than one adult worker, standard errors are corrected for clustering at the household level. This parallels the Bundorf and Pauly (2002) approach for defining affordability of health insurance. They estimate the probability that individuals purchase insurance and then use predicted probabilities to implicitly define affordability. For example, an individual who does not purchase insurance, but has a predicted probability of being insured in excess of 70 percent is presumed to be uninsured for reasons other than unaffordability. Their underlying rationale is that if most people in similar economic circumstances obtain coverage (and, by definition, could afford 
coverage), the lack of coverage among others facing similar financial constraints should not be ascribed to inability to afford it.

In the mismatch context, analogous definitions are based on the probability of being insured as a function of worker characteristics. We then define as mismatches those individuals with high predicted probabilities of insurance, but who are uninsured and work for a firm that does not offer them coverage. Of course, these workers might simply have low demand for coverage because of unobserved factors. If so, their lack of ESI eligibility would actually represent appropriate labor market matching. The likelihood of such an errant interpretation is lessened: 1) if the observed variables are good predictors of insurance preferences; and 2) by choosing a relatively high threshold probability to categorize a worker as being mismatched. Conversely, workers who fall short of the threshold probability, and hence are classified as properly sorted low demanders, might actually be mismatched if they have strong, unobserved preferences for insurance.

Bundorf and Pauly use predicted probability thresholds of 0.5, 0.6, 0.7, and 0.8. We add a 0.9 threshold. For a worker who exceeds a high threshold but is not offered/eligible for coverage to be appropriately matched, the negative unobserved component of their insurance preference would have to be substantial. Thus, higher thresholds yield more conservative mismatch classifications. However, because insurance is strongly correlated with income, high income families will, all else equal, have a high predicted probability of holding insurance. If not offered/eligible for their own coverage, relatively well-to-do households who value health insurance highly could presumably afford to purchase non-group coverage. Therefore, if we observe a worker in a relatively high income household who is not offered/eligible for insurance and remains uninsured rather than purchasing non-group coverage, it appears reasonable to infer 
that they have a substantial, negative unobserved preference for insurance. ${ }^{3}$ To avoid errantly classifying such workers as "high demand mismatches”, we apply a family income cutoff of $\$ 60,000 .{ }^{4}$ In other words, we only consider these workers as mismatched if they exceed the predicted probability of insurance threshold and do not reside in a household with an income high enough that they presumably could have afforded non-group coverage as a viable, though higher cost, alternative to remaining uninsured. Using the entire sample, we estimate each worker's predicted probability of 1) holding private coverage of any type, and 2) holding private or public coverage of any type. These predicted probabilities serve as proxies for the strength of the worker's demand for health insurance. We prefer the estimates based on private coverage because they are not subject to public program eligibility criteria that may be unrelated to the worker’s inherent demand for insurance.

Finally, we examine how much the estimated prevalence of mismatches varies across CTS sites and with aggregate labor market characteristics such as the distribution of employment across sectors and the size (population) and density (population per square mile) of the labor market.

\section{Data}

The primary data source is the 2003 Community Tracking Household Survey (CTS). This survey includes 25,000 households in 51 metropolitan statistical areas (MSA) and 9 rural sites and was conducted by the Center for Studying Health System Change. Survey sites were chosen in order to generate a nationally representative sample, providing demographic, health status, income, employment and insurance information for each individual. Since the sampling

\footnotetext{
${ }^{3}$ We are indebted to Tom DeLeire for this point.

${ }^{4} 32.6$ percent of workers who were not offered/eligible for their own ESI and remained uninsured resided in households with incomes over $\$ 60,000$ (vs. 44.8 percent in the entire sample).
} 
unit is the household, we are able to use family-level information on insurance, income, health status and family size, to complement individual information.

The primary strength of the CTS relative to other national household surveys is its detailed information on health insurance coverage for each household member, including sources of coverage, employer offers of coverage, and respondents' decision to accept or decline those offers. We distinguish between private group coverage, private non-group coverage, public coverage and uninsurance. Private group coverage consists of employment related insurance (from a worker's own job or that of a family member), as well as coverage from a source outside the family unit. Private non-group insurance consists of insurance purchased in the individual market. Public insurance includes Medicare, Medicaid, Military, and other public coverage.

Our analysis sample includes 19,109 working individuals between 18 and 64 years old. These individuals represent 103 million of the US population. The unemployed and the selfemployed are excluded. We also exclude non-working dependents, including spouses, of individuals included in the sample. All multivariate analyses have corrected standard errors for the complex survey design of the CTS. Several labor market characteristics (e.g., sector of employment) are calculated at the site level from the CTS data and several additional labor market characteristics (e.g., population density) are obtained from Census data.

\section{Results}

Table 1 reports descriptive statistics by ESI offer status. Overall, 14 percent of workers aged 18-64 were uninsured. Among those offered and eligible for ESI from their employer, 5 percent were uninsured. Twenty-one percent of workers who declined an offer of ESI and 42 percent of those not offered/eligible for ESI were uninsured. Statistically significant $(\mathrm{p}<0.001)$ 
differences emerge by offer status. For example, those not offered or eligible for ESI tend to be younger, have lower incomes, and be more likely to work for small firms than workers who were offered and eligible for ESI.

\section{Classifying workers as "matched" or "mismatched" in the labor market}

Following the conventions described above, we classify workers into the categories described in Figure 2. In six of the seven subgroups defined by ESI offer status and insurance status, workers are uniformly classified with respect to the appropriateness of labor market sorting. For the other subgroup, uninsured workers not offered/eligible for ESI, the predicted probability of being insured is used to split workers into those who are matched (low demand for insurance) and mismatched (high demand for insurance). Because the "high demand mismatches” remain uninsured and did not have the option of ESI without switching jobs, they are the workers most likely to generate interest among policy-makers concerned with the functioning of the employer-based health insurance system.

Because the accuracy of this split is important to our conclusions, the performance of the predicted insurance probability models will be described in some detail. The distribution of predicted probability, our proxy for demand for insurance, is reported for the entire sample in Table 2. The model generates substantial variation in predicted probabilities, and hence might reasonably differentiate between high and low insurance demanders. Since the insurance rate among the working population is high (78.1percent for private insurance and 86.1 percent for any insurance), it is not surprising that the models estimate a high probability of coverage for

most workers (e.g., the $25^{\text {th }}$ percentile predicted probability of private coverage is 72 percent). However, the interquartile range of the distribution of predicted probabilities is nearly $20 \%$ and 
some workers have low predicted probabilities (e.g., 29 percent probability of private coverage at the $5^{\text {th }}$ percentile, approximately one-third of the mean value). The full models are reported in Appendix Table 1. In terms of predictions among specific subgroups, the proportions of workers exceeding predicted demand thresholds ranging from 0.5 to 0.9 are reported in Table 3A for private coverage and Table 3B for any coverage. Comparing across subgroups, the model predicts substantially different probabilities of holding insurance.

Three groups of workers share high predicted probabilities of insurance. Workers who accept their employer's offer of ESI have very high predicted probabilities of coverage (86 percent exceed the 0.7 threshold for private coverage; 61 percent exceed the 0.9 threshold). The model predicts even higher probabilities of coverage among workers who declined their own ESI offer in favor of obtaining insurance from another private group or public source, and among workers not offered/eligible for their own ESI but who had private, group coverage from another source. Generally, both of these types of workers are members of two income households with at least one offer of ESI.

On the other side of the spectrum, the predicted probability is low for three groups: those who declined an offer of ESI and remained uninsured (8.4 percent exceeded the 0.9 threshold for private coverage; 38.4 percent exceeded the 0.7 threshold); those who were not offered/eligible for ESI but obtained public coverage (13.6 percent exceeded the 0.9 threshold for private coverage; 34.1 percent exceeded the 0.7 threshold); and those not offered/eligible for ESI who remained uninsured (6.3 percent exceed the 0.9 threshold for private coverage; 28.1 percent exceed the 0.7 threshold). 
Finally, workers holding non-group coverage ranked in the middle in terms of predicted probabilities of coverage. 47.2 percent exceeded the 0.9 threshold for private coverage while 79.3 percent exceeded the 0.7 threshold.

\section{A. Labor market "matches"}

Our match and mismatch classifications for the 19,109 workers are summarized in Table 4 and Figure 3. Three types of workers are defined as "insured matches." The largest of these groups is workers who accept their employer's offer of ESI (58.8 percent of the US working population aged 18-64). Similarly, based on our assumption that workers not offered or eligible for ESI but who obtained other private group or public coverage do not desire to trade wages for an offer of ESI, the not offered/eligible subgroups insured privately (9.2 percent) and publicly 3.4 percent) are also classified as appropriately matched. Most (69 percent) workers who were not offered/eligible for ESI and obtained coverage through another private group source had family incomes above three times the Federal Poverty Level (3xFPL). This indicates that even relatively well off, dual earner families (who might be expected to primarily find jobs with offers of ESI) were often able to sort in a manner that allowed one earner to obtain and accept an offer of ESI while the other earner did not have to accept a wage tradeoff for a second offer of ESI. Scaled to the national level, these three types of "insured matches" constitute 73,789,443 workers, or 71.4 percent of the working US population. That is, almost three fourths of workers either take up coverage through their own employer, or find an alternate source without sacrificing cash wages.

In addition to these insured matches, uninsured workers who are not offered ESI and appear to have low demand for insurance are also classified as having found a good match 
between their preferences and their employer’s ESI policy. Using the predicted insurance probability models to assess demand for insurance, uninsured workers without an offer of ESI are classified as well-matched "low demanders" if their predicted probability lies below a threshold value, or as mismatched "high demanders" otherwise. The choice of threshold involves a tradeoff between Type I and Type II errors. A high threshold results in more mismatched high demanders being misclassified as properly matched low demanders, and vice versa. Tables 3a and $3 \mathrm{~b}$ present the results for a range of thresholds and two definitions of insurance (private or any coverage) in order to allow readers to reach their own conclusions. However, for purposes of discussion we will focus on our preferred threshold of 0.7. The choice of a relatively high threshold conservatively limits the risk of misclassifying workers with low unobserved demand for insurance as mismatched high demanders. Even for those barely surpassing it, seven out of ten similar workers hold insurance. Further, the models differentiate predicted insurance probabilities sufficiently well that a considerable number of workers do fall below the 0.7 threshold. Of the 1,166 uninsured workers not offered/eligible for ESI with income less than $\$ 60,000$ in 2002, 886 fall below the 0.7 threshold in the private coverage model and are classified as properly matched low demanders.

In total, the four types of matched workers include 15,273 workers (79.6 percent of the weighted sample) when employing a 0.7 threshold in the private insurance model to classify uninsured workers who were not offered/eligible for ESI. Thus, nearly four out of five workers appear to enjoy a good match between their inferred preferences for ESI and their employer's decision to offer or not offer coverage.

\section{B. Labor market “mismatches"}


Mismatches include two types of insured workers and two types of uninsured workers.

The insured mismatches include those declining their own offer of ESI who hold coverage from another private group or public source (12.4 percent) and those purchasing non-group coverage (2.4 percent). Most privately insured, ESI decliners live in two earner households with two offers of ESI, and are classified as mismatches because of the likely wage tradeoff being made for which little value is being generated (aside from some option value of having a redundant source of coverage). Non-group insured workers are classified as mismatches because they likely face high premiums, medical underwriting, and limitations on coverage. Hence, we believe that these workers would generally prefer an offer of ESI.

Uninsured mismatches consist of two types of workers. The first is those who decline an ESI offer despite not taking up coverage from another source. There were 514 of these uninsured ESI decliners (3.4 percent), who presumably accepted some degree of wage tradeoff for access to a benefit that they did not value enough to purchase. The second type is those who do not receive an offer of ESI but are deemed high insurance demanders by virtue of exceeding a pre-specified threshold value for predicted probability of coverage. These high insurance demand mismatches are workers who we infer would have valued an offer but did not receive one. Using the 0.7 threshold value in the private insurance model, 280 of the 1,166 uninsured workers not offered/eligible for insurance and incomes less than $\$ 60,000$ exceeded the threshold (representing 2.2 percent of the weighted population). The comparable figures using the 0.7 threshold in the any insurance model are 451 workers in the sample (representing 3.5 percent of the US working population). ${ }^{5}$ These workers could be considered "involuntarily uninsured"

\footnotetext{
${ }^{5}$ Had we not applied the $\$ 60,000$ family income threshold, 2.7 percent of the weighted sample would have been deemed involuntarily uninsured by virtue of exceeding the 0.7 predicted probability of insurance using the private insurance model (4.7 percent of the weighted sample using the any insurance model).
} 
because we believe there is a high probability that they would want and take up an offer of ESI. ${ }^{6}$

The fact that they have not purchased coverage in the private group market may indicate that they are unwilling to pay the substantially higher premiums relative to ESI, or that they are unable to purchase such coverage because of practices such as underwriting (those holding nongroup coverage in the sample were substantially healthier than average, consistent with access being limited for those with health problems).

Overall, 4,029 workers (20.4 percent of the weighted sample when using the 0.7 threshold in the private insurance model to classify uninsured workers not offered/eligible for ESI) were classified in one of the four mismatch categories. These individuals represent 21,040,776 working Americans aged 18-64. Thus, more than one worker out of five suffers from a mismatch between their inferred preferences for ESI and their employer's decision to offer or not offer coverage according to our classification conventions.

\section{Labor market characteristics and mismatch}

The prevalence of mismatches varied across CTS sites. The prevalence of mismatches of any type ranged from 17.3 percent at the $25^{\text {th }}$ percentile to 23.1 percent at the $75^{\text {th }}$ percentile. Comparable interquartile ranges across sites for the prevalence by specific types of mismatch were non-group insured (1.0 percent at $25^{\text {th }}$ percentile, 3.6 percent at $75^{\text {th }}$ percentile), decline ESI

\footnotetext{
${ }^{6}$ An alternative to using the "threshold" method of determining what fraction of workers not offered or eligible for ESI with family incomes $<\$ 60,000$ are mismatched (i.e., would prefer a job that offered ESI) would be to directly use the predicted probabilities to calculate the expected number of workers who desire and take up an offer of ESI with a better labor market match. The problem with such a calculation is that its validity relies on the assumption that the model error term has a mean of zero in this subgroup. To the extent that people with low unobserved preferences for insurance sort into jobs that do not offer coverage and leave them uninsured, the mean error term in this subgroup would be negative. Thus, we prefer the more conservative estimate based on exceeding the 0.7 threshold.
} 
but obtain other coverage (10.1 percent, 14.9 percent), decline ESI and remain uninsured (1.6 percent, 4.7 percent), and uninsured worker who were not offered/eligible for ESI and had high predicted demand for health insurance ( 0.5 percent, 3.4 percent; based on private insurance model with 0.7 predicted probability threshold and \$60,000 family income limit).

Labor market mismatches could occur for a variety of reasons, but we expect that 'denser’ labor markets would exhibit fewer mismatches. To explore this possibility, we characterized CTS sites by size and examined whether the probability of 'mismatch' was greater for workers in smaller sites. In addition, we correlated several labor market characteristics with mismatches to determine if certain labor market conditions impede matching.

Due to the relatively small number of sites (60), few of the correlations were statistically significant, but most were in the hypothesized directions. As expected, labor market size and density are inversely correlated with prevalence of mismatches, but the correlations are not statistically significant. The correlation between the total percent of workers mismatched and site population density and population are $r=-0.213(p=.12)$ and $r=-0.16(p=.25)$, respectively. Looking at the specific types of mismatch, these overall correlations were driven by reductions in the prevalence of workers who declined ESI and held coverage from another source. This is consistent with larger and denser labor markets facilitating workers’ ability to avoid making a wage tradeoff for a redundant source of coverage that would not be taken up.

Percent of area employment in specific industries prone to offer or not offer coverage was also weakly related to the prevalence of mismatches. For example, in areas where a substantial fraction of employment was in industries that traditionally offered coverage (e.g. manufacturing) the prevalence of mismatches for high demanders was low. The correlation between the percent share of an area's employment in manufacturing and the prevalence of high demand mismatches 
was $-0.216,(p=.12)$. The logic behind this result is that if many of the firms in a labor market offer coverage, high demanders are better able to find jobs with coverage. While this may not be surprising, in the context of sorting it suggests that workers do not completely sort across labor markets in a way that would lead the distribution of worker preferences to mirror the insurance offerings of the set of employers in an area.

Finally, higher percent of public sector (government) employment is weakly correlated with more total mismatches $(r=0.232, \mathrm{p}=.10)$. Thus, benefit offerings may be relatively more responsive to worker preferences in the private sector.

\section{Discussion and Policy Implications}

The objective of this paper is to estimate the number of workers whose preferences for health insurance are not optimally matched by their employer's decision on whether or not to offer them coverage. The literature has reported a variety of findings consistent with the conclusion that labor market sorting occurs, but is incomplete. Although the literature often discusses the issue of sorting in the labor market, to our knowledge this is the first comprehensive estimate of the prevalence of missorting.

We classified workers as either being properly matched or mismatched on the basis of observed ESI offer status and insurance status, along with a proxy for insurance demand derived from multivariate models predicting the probability of coverage. Using this classification scheme, it appears that the employment-based health insurance system works well for a large majority of workers, at least in terms of whether or not the worker's desire for health insurance matches their employer's offer decision. We do not explore more subtle manifestations of 
mismatching such as workers who have insurance but would prefer a plan not offered by their current employer. Nonetheless, more than one worker out of five appears to be mismatched. Our classifications are necessarily based on a number of strong assumptions, and short be interpreted as only a rough estimated of the magnitude of missorting relative to an ideal, frictionless labor market.

We identify four types of mismatched workers, each raising distinct health policy issues. The most common type of mismatch occurs when a worker who has obtained coverage elsewhere declines an offer of ESI (12.4 percent of the entire sample). Given our belief, based upon the preponderance of evidence in the literature, that these workers do not recoup the full value of the declined offer in the form of higher wages, this type of mismatch results in workers receiving lower cash wages than would be available in an ideal labor market where they could have obtained a similar job without an offer of insurance. Since these workers hold other insurance and often come from middle to high income, two earner households, this loss of potential income may not create substantial policy concern. If the "option value” of holding a secondary source of insurance has risen over time along with health insurance premiums and cutbacks in employer coverage, the welfare loss to this group would be further mitigated. However, it should be noted that even in this generally well-off group, 8.8 percent have family incomes below 1.5 times the Federal poverty level and an additional 17.5 percent fall below 3 times the Federal poverty level.

Uninsured workers who decline ESI (3.4 percent) suffer a qualitatively similar welfare loss from missorting due to loss of potential cash income, but are much more likely to be in lower income groups. Like the uninsured workers who are not offered/eligible for ESI and have 
low demand for insurance, the uninsured decliners of ESI can be thought of as "voluntarily uninsured.”

Over time, take-up rates for ESI have declined concurrently with an increase in copremiums charged by employers. For example, Farber and Levy (2000) analyze Current Population Survey data on take-up from 1988 to 1997, concluding that take-up fell from 88.6 percent in 1988 to 85.0 percent in 1997. Their 1997 take-up figure is slightly higher than our figure based on the CTS, but the trend may indicate that mismatches resulting from declined ESI offers are being more common.

Non-group insured workers (2.4 percent) may be of policy interest given the high premiums and medical underwriting they are likely to face, as well as the potentially tenuous nature of their coverage from year-to-year. Indeed, the good health of this group, on average, illustrates the difficulties of relying on non-group coverage as a viable alternative to ESI and corroborates Hadley and Reschovsky’s (2003) finding that non-group coverage is half as likely among those in poor or fair health relative to those in good or excellent health. Hadley and Reschovsky also conclude that non-group premiums are up to 50 percent higher for those with health problems. Better labor market sorting (alternatively, incentives such as tax credits that encourage employers of workers currently holding non-group coverage to offer ESI) would help these workers obtain group coverage and would benefit them through lower premiums (e.g., via lower administrative loading) and with the better protection from the risk of facing higher future premiums if their health status deteriorates (Pauly, Kunreuther and Hirth, 1995).

Finally, uninsured workers who were not offered/eligible for ESI and exceeded a threshold value for the predicted probability of coverage were classified as high demand mismatches. These workers are deemed to be "involuntarily uninsured." Using the 0.7 threshold 
value, this group accounted for 2.2 percent of workers in the private insurance model (3.5 percent in the any insurance model). With a civilian labor force aged 20 and over of approximately 130 million in 2003 (ftp://ftp.bls.gov/pub/suppl/empsit.cpseea3.txt), these rates would imply about 2.3 million to 3.6 million workers nationally, based respectively on the private and any insurance models. With an average number of uninsured individuals per household among the sample workers classified as high demand mismatches of 2.03, this group would account for approximately 4.7 million to 7.3 million uninsured persons nationally. ${ }^{7}$ This represents 10.9 percent to 16.9 percent of the estimated 43.3 million uninsured persons in the United States and 14.5 percent to 22.5 percent of the 32.5 million uninsured persons with at least one non-self-employed worker in their family (tabulations based on 2003 Current Population Survey data; http://www.umich.edu/ eriu/fastfacts/cps2002_1.html). While perfect labor market sorting is an unattainable ideal, these estimated numbers of workers who could gain insurance if they found a better match is sizeable relative to the numbers who could gain insurance under various proposed policies. Glied and Gould (2005) recently estimated that expansions of Medicaid coverage to include all adults under 1.33xFPL and the Bush tax credit proposal could each reduce the number of uninsured by about 11 percent while a smaller firm tax credit would reduce the number of uninsured by only 3 percent.

The prevalence of mismatches between worker preferences and employer decisions to offer health insurance has implications for the desirability of tying insurance to employment. As noted by Blumberg and Nichols (2004), it is not known whether the magnitude of search costs renders the observed prevalence of apparent mismatches inefficiently large, but they surmise that efficiency could be enhanced by "appropriate interventions." In particular, efforts to improve

\footnotetext{
${ }^{7}$ Because our sample frame is workers rather than household, the 650 workers in the high demand mismatch group come from 467 unique household. These projections at the household level are corrected to prevent double-counting of the $28 \%$ of households with more than one worker in the high demand mismatch category.
} 
access to or affordability of ESI or alternative public coverage to lower income workers could be appropriate. Lower income workers may not have the luxury of protracted job searches to find one of the relatively scarce low wage jobs that comes with insurance. To the extent that lower income workers with relatively high demand for insurance are employed alongside workers who have relatively low demand for coverage, employers' decisions to not offer coverage may reflect the preferences of their typical worker more than of the higher demand subset of workers. The extent to which smaller employers dominate in the hiring of lower wage workers reinforces access problems through the higher administrative loadings that would exist if the firm did decide to offer coverage.

A policy approach that builds on the private health insurance market is suggested by Pauly and Herring (2001), who propose refundable tax credits for health insurance, coupled with reforms in the small group and non-group insurance market to help increase coverage rates. Given that workers who did not have access to ESI and reported health problems did not fare well in finding alternative sources of private coverage, such policies could be beneficial. While overall price elasticities of insurance demand among workers without ESI are low (Marquis and Long 1995, Chernew, Frick and McLaughlin 1997), it is reasonable to expect that those high demand workers mismatched in the labor market would respond to tax credits more strongly than the average worker without ESI.

Feder et al. (2001) suggest the alternative approach of expanding public coverage. To the extent that even with a tax credit, lower income workers and families with poor health status continue to find it difficult to access private coverage, a public-insurance based strategy of compensating for labor market mismatches would be appropriate for at least a subset of workers. Blumberg and Nichols (2004) note that missorting implies that there "could be more of a market 
failure in private health insurance than previously thought,” and suggest further exploration of non-labor market mechanisms (public or private) for insurance purchase.

Missorting also has implications for policy simulations. With good sorting, firm behavior and, ultimately, coverage rates would show little response to interventions targeting employers (e.g., subsidies to employers, low-cost insurance pools) because employers not initially offering ESI would be those whose workers have low demand for ESI. Conversely, if mismatches are common, a significant number of high demand workers would be employed by firms who do not offer insurance, and interventions encouraging employer-sponsored coverage would be more effective. Policy simulations should account for measures of presumptive mismatch and geographic variation in their prevalence to refine estimates of the response to and welfare effects of proposed policies. 


\section{References}

Blumberg, L.J. and L.M. Nichols. 2001. "The Health Status of Workers Who Decline EmployerSponsored Insurance,” Health Affairs. 20 (6), 180-7.

Blumberg, L.J. and L.M. Nichols. 2004. “Why Are So Many Americans Uninsured?,” in Health Policy and the Uninsured: Setting the Research Agenda, C.G. McLaughlin, ed., Urban Institute Press.

Bundorf, M. K. and M. V. Pauly. 2002. “Is Insurance Affordable for the Uninsured?” National Bureau of Economic Research Working Paper No. 9281, p. 1-43

Center for Studying Health System Change. 2000. Community Tracking Household Survey, 1996-97, and Followback Survey, 1997-98: (Computer File; Restricted Use Version]. $2^{\text {nd }}$ ICPSR version. Washington, DC: Center for Studying Health System Change [producer]. Inter-university Consortium for Political and Social Research [distributor].

Chernew M., Frick K. and McLaughlin C.G. 1997. "The demand for health insurance coverage by low-income workers: can reduced premiums achieve full coverage?,” Health Services Research 32(4):453-70.

Chernew, M.E. and R.A. Hirth. 2004. "Modeling the Causes and Consequences of Lack of Health Insurance Coverage: Gaps in the Literature," Health Policy and the Uninsured: Setting the Research Agenda, C.G. McLaughlin, ed., Urban Institute Press.

Currie, J., and B. C. Madrian. 1999. "Health, Health Insurance and the Labor Market.” In Handbook of Labor Economics, edited by O. Ashenfelter, and D. E. Card. Volume 3, Part 3 p. 3309-3390. New York: Elsevier Science Publishing Company.

Feder, J., L. Levitt, E. O’Brien and D. Rowland. 2001. “Covering the Low-Income Uninsured: The Case for Expanding Public Programs,” Health Affairs January/February 2001 pp. 2739.

Farber H.S. and Levy H. 2000. "Recent trends in employer-sponsored health insurance coverage: are bad jobs getting worse?” Journal of Health Economics 2000 Jan;19(1):93-119.

Feldman, R., B. Dowd, S. Leitz, and L. A. Blewett. 1997. "The Effect of Premiums on the Small Firm's Decision to Offer Health Insurance.” The Journal of Human Resources 32 (4): 635-659,

Glied, S., and D. Gould. 2005. "Variations in the Impact of Health Coverage Expansion Proposals across States,” Health Affairs, Web Exclusive W5:259-271.

Goldstein, G., and M. V. Pauly. 1976. “Group Health Insurance as a Local Public Good.” In The Role of Health Insurance in the Health Services Sector. Richard Rossett, ed. 73-110. 
New York: Neale Watson Academic Publications for the National Bureau of Economic Research.

Gruber, J., and M. Lettau. 2000. "How Elastic is the Firm’s Demand for Health Insurance?” National Bureau of Economic Research Working Paper No. 8021.

Hadley, J. and J. D. Reschovsky. 2002. "Small Firms' Demand for Health Insurance: The Decision to Offer Insurance.” Inquiry 39 (2):118-138.

Hadley, J. and J. D. Reschovsky. 2003. "Health and the Cost of Nongroup Insurance. Inquiry 40 (3):235-53.

Long, S. H. and S. M. Marquis. 1993. "Gaps in Employer Coverage: Lack of Supply or Lack of Demand?” Health Affairs 12: 282-294

Long, S.H. and S. M. Marquis. 1995. "Worker Demand for Health Insurance in the Non-Group Market,” Journal of Health Economics 14: 47-63.

McLaughlin, C.G., and W.K. Zellers. 1993. "The Shortcomings of Voluntarism in the SmallGroup Insurance Market,” Health Affairs 11(2):28-40.

Monheit, A. C. and J. P. Vistnes. 1999. "Health Insurance Availability and the Workplace: How Important Are Worker Preferences?” The Journal of Human Resources 34 (4): 770-785

Moran, J. R., M. E. Chernew and R. A. Hirth. 2001. "Preference Diversity and the Breadth of Employee Health Insurance Options.” Health Services Research 36(5):911-935.

Pauly, M. V., H. Kunreuther and R. A. Hirth. 1995. "Guaranteed Renewability in Insurance”, Journal of Risk and Uncertainty 10( 2) p.143 - 156

Pauly, M. V. and B. Herring. 2001. "Expanding Insurance Via Tax Credits: Trade-offs and Outcomes,” Health Affairs (January/February): 9-26.

Pauly, M.V. and A. Percy. 2000. "Cost and Performance: A Comparison of the Individual and Group Health Insurance Markets.” Journal of Health Policy, Politics and Law 25(1): 926.

Scott, F.A., M.C. Berger, D.A. Black. 1989. "Effects of the Tax Treatment of Fringe Benefits on Labor Market Segmentation.” Industrial \& Labor Relations Review 42(2): 216-229.

States Health Access Data Assistance Center (SHADAC), University of Minnesota. 2004. "Characteristics of the Uninsured: A View from the States," prepared for the Robert Wood Johnson Foundation. 
Figure 1

Conceptual Framework for Defining Mismatches

\begin{tabular}{|l|l|l|}
\hline & Employer offers coverage & $\begin{array}{l}\text { Employer does not offer } \\
\text { coverage }\end{array}$ \\
\hline $\begin{array}{l}\text { Worker wants coverage } \\
\text { through employer }\end{array}$ & Appropriate sorting & Mismatch \\
\hline $\begin{array}{l}\text { Worker does not want } \\
\text { coverage through } \\
\text { employer }\end{array}$ & Mismatch & Appropriate sorting \\
\hline
\end{tabular}


Figure 2

Classifying Workers Using Conceptual Framework

\begin{tabular}{|l|l|l|}
\hline & Employer offers coverage & $\begin{array}{l}\text { Employer does not offer } \\
\text { coverage }\end{array}$ \\
\hline $\begin{array}{l}\text { Employee wants coverage } \\
\text { through their employer }\end{array}$ & Appropriate sorting & $\underline{\text { Mismatch }}$ \\
Accept offer of ESI & $\begin{array}{l}\text { Purchase non-group } \\
\text { insurance }\end{array}$ \\
\hline $\begin{array}{l}\text { Employee does not want } \\
\text { coverage through their } \\
\text { employer }\end{array}$ & Mismatch & $\begin{array}{l}\text { Uninsured with high } \\
\text { demand for ESI }\end{array}$ \\
\hline $\begin{array}{l}\text { Decline ESI, hold other } \\
\text { private group or public } \\
\text { coverage }\end{array}$ & $\begin{array}{l}\text { Appropriate sorting } \\
\text { cold other private group }\end{array}$ \\
\hline Decline ESI, uninsured & $\begin{array}{l}\text { Hold public coverage } \\
\text { Uninsured with low demand } \\
\text { for ESI }\end{array}$ \\
\hline
\end{tabular}

1“Wanting” coverage is not measured directly through survey questions, but is inferred via a combination of revealed preference arguments based on the worker's actual behavior and empirical estimates of the worker's demand for coverage (see text). 


\begin{tabular}{|c|c|c|c|c|c|c|c|c|c|c|}
\hline & \multicolumn{9}{|c|}{ TABLE 1} & \\
\hline & \multicolumn{10}{|c|}{ Descriptive Statistics } \\
\hline & \multicolumn{2}{|l|}{ All } & \multicolumn{2}{|c|}{ Offered \& Eligible } & \multicolumn{2}{|l|}{ Accepts } & \multicolumn{2}{|l|}{ Declines } & \multicolumn{2}{|c|}{ Not Offered/Eligible } \\
\hline & $\mathrm{N}=19,109$ & & $\mathrm{~N}=14,928$ & & $\mathrm{~N}=11,71$ & & $N=3,212$ & & $\mathrm{~N}=4,181$ & \\
\hline Variable & Mean & S.D. & Mean & S.D. & Mean & S.D. & Mean & S.D. & Mean & S.D. \\
\hline Own ESI & 0.588 & 0.01 & 0.783 & 0.01 & 1 & --- & 0 & ---- & 0 & ---- \\
\hline Private Group & 0.781 & 0.01 & 0.917 & 0.01 & 0.999 & 0.00 & 0.620 & 0.02 & 0.370 & 0.02 \\
\hline Private Non-Group & 0.024 & 0.00 & 0.007 & 0.00 & 0 & ---- & 0.033 & 0.00 & 0.073 & 0.01 \\
\hline Public & 0.057 & 0.00 & 0.031 & 0.00 & 0.001 & 0.00 & 0.137 & 0.02 & 0.136 & 0.01 \\
\hline Uninsured & 0.139 & 0.01 & 0.046 & 0.00 & 0 & ---- & 0.209 & 0.01 & 0.420 & 0.02 \\
\hline Age & 39 & 0.15 & 41 & 0.17 & 42 & 0.17 & 38 & 0.32 & 34 & 0.41 \\
\hline Male & 0.527 & 0.01 & 0.543 & 0.01 & 0.569 & 0.01 & 0.448 & 0.01 & 0.481 & 0.02 \\
\hline Black & 0.108 & 0.01 & 0.110 & 0.01 & 0.112 & 0.01 & 0.104 & 0.02 & 0.101 & 0.01 \\
\hline Hispanic & 0.125 & 0.02 & 0.104 & 0.01 & 0.094 & 0.01 & 0.140 & 0.02 & 0.190 & 0.03 \\
\hline Other Race & 0.049 & 0.00 & 0.048 & 0.00 & 0.048 & 0.00 & 0.047 & 0.01 & 0.053 & 0.01 \\
\hline Spanish & 0.071 & 0.03 & 0.073 & 0.03 & 0.070 & 0.03 & 0.087 & 0.04 & 0.062 & 0.03 \\
\hline Married & 0.611 & 0.01 & 0.648 & 0.01 & 0.633 & 0.01 & 0.701 & 0.01 & 0.499 & 0.02 \\
\hline Family Income & 62,814 & 904 & 66,722 & 907 & 66,265 & 944 & 68,369 & 1,347 & 51,025 & 1,503 \\
\hline Income $<1.5 \times \mathrm{FPL}^{*}$ & 0.145 & 0.01 & 0.089 & 0.01 & 0.074 & 0.01 & 0.147 & 0.01 & 0.314 & 0.02 \\
\hline $\begin{array}{r}\text { High School } \\
\text { Education or Less }\end{array}$ & 0.409 & 0.01 & 0.360 & 0.01 & 0.347 & 0.01 & 0.407 & 0.02 & 0.558 & 0.01 \\
\hline Excellent Health & 0.643 & 0.01 & 0.662 & 0.01 & 0.665 & 0.01 & 0.650 & 0.01 & 0.589 & 0.02 \\
\hline Good Health & 0.257 & 0.01 & 0.253 & 0.01 & 0.255 & 0.01 & 0.246 & 0.01 & 0.268 & 0.02 \\
\hline Fair Health & 0.087 & 0.00 & 0.075 & 0.00 & 0.070 & 0.00 & 0.093 & 0.01 & 0.124 & 0.01 \\
\hline Poor Health & 0.012 & 0.00 & 0.010 & 0.00 & 0.009 & 0.00 & 0.012 & 0.00 & 0.019 & 0.00 \\
\hline Firm Size $100+$ & 0.878 & 0.01 & 0.911 & 0.00 & 0.915 & 0.01 & 0.897 & 0.01 & 0.779 & 0.01 \\
\hline Firm Size 25-100 & 0.051 & 0.00 & 0.048 & 0.00 & 0.046 & 0.00 & 0.055 & 0.01 & 0.061 & 0.01 \\
\hline Firm Size 10-25 & 0.036 & 0.00 & 0.023 & 0.00 & 0.022 & 0.00 & 0.031 & 0.01 & 0.072 & 0.01 \\
\hline Firm Size 1-10 & 0.035 & 0.00 & 0.017 & 0.00 & 0.018 & 0.00 & 0.017 & 0.00 & 0.088 & 0.01 \\
\hline
\end{tabular}


Table 2

Distribution of Predicted Coverage Probabilities

$\begin{array}{lcccccccc}\text { Private Coverage } & \text { Mean } & \text { Min } & \mathbf{5 \% i l e} & \mathbf{2 5} \% \text { ile } & \mathbf{5 0} \% \text { ile } & \mathbf{7 5} \% \text { ile } & \mathbf{9 5} \% \text { ile } & \text { Max } \\ \text { Model } & 0.8048 & 0.0107 & 0.2915 & 0.7204 & 0.9101 & 0.9608 & 0.9857 & 0.9974 \\ \text { Any Insurance Model } & 0.8622 & 0.0329 & 0.4548 & 0.8112 & 0.9434 & 0.9789 & 0.9933 & 0.9994\end{array}$


Table 3a

Predicted Demand by Offer and Insurance Status Thresholds for Private Insurance Predicted Demand

\begin{tabular}{|c|c|c|c|c|c|c|c|c|c|c|c|c|}
\hline & \multicolumn{12}{|c|}{ Inresnolas tor Private insurance Prealctea Demana } \\
\hline & \multicolumn{4}{|c|}{$>.90$} & \multicolumn{2}{|c|}{$>.80$} & \multicolumn{2}{|c|}{$>.70$} & \multicolumn{2}{|c|}{$>.60$} & \multicolumn{2}{|c|}{$>.50$} \\
\hline & $\mathbf{n}$ & Population & Mean & SD & Mean & SD & Mean & SD & Mean & SD & Mean & SD \\
\hline Non-Group Insured & 454 & $2,436,011$ & 0.472 & 0.05 & 0.682 & 0.03 & 0.793 & 0.03 & 0.868 & 0.03 & 0.896 & 0.03 \\
\hline Insured ESI Decliners & 2588 & $12,793,682$ & 0.681 & 0.02 & 0.807 & 0.02 & 0.869 & 0.01 & 0.888 & 0.01 & 0.921 & 0.01 \\
\hline Uninsured ESI & & & & & & & & & & & & \\
\hline $\begin{array}{r}\text { Decliners } \\
\text { Not Offered/Eligible }\end{array}$ & 514 & $3,535,389$ & 0.084 & 0.02 & 0.203 & 0.03 & 0.384 & 0.04 & 0.506 & 0.04 & 0.620 & 0.04 \\
\hline $\begin{array}{r}\text { Uninsured, } \\
\text { Income>\$60K } \\
\text { Not Offered/Eliaible }\end{array}$ & 221 & $1,339,762$ & 0.207 & 0.04 & 0.426 & 0.07 & 0.567 & 0.07 & 0.886 & 0.03 & 0.959 & 0.02 \\
\hline $\begin{array}{r}\text { Uninsured, } \\
\text { Income }<\$ 60 \mathrm{~K}\end{array}$ & 1,166 & $9,468,557$ & 0.043 & 0.01 & 0.144 & 0.02 & 0.240 & 0.03 & 0.356 & 0.02 & 0.460 & 0.03 \\
\hline $\begin{array}{r}\text { Offered, Eligible \& } \\
\text { Accept ESI }\end{array}$ & 11716 & $60,749,029$ & 0.607 & 0.01 & 0.779 & 0.01 & $-\mathrm{i} 0.860$ & 0.01 & 0.908 & 0.01 & 0.945 & 0.01 \\
\hline $\begin{array}{l}\text { Not Offered/Eligible } \\
\text { with Private (group) }\end{array}$ & & & & & & & & & & & & \\
\hline Coverage & 1890 & $9,532,178$ & 0.664 & 0.02 & 0.832 & 0.02 & 0.879 & 0.01 & 0.913 & 0.01 & 0.937 & 0.01 \\
\hline $\begin{array}{r}\text { Not Offered/Eligible } \\
\text { with Public Coverage }\end{array}$ & 560 & $3,508,223$ & 0.136 & 0.02 & 0.235 & 0.03 & 0.341 & 0.03 & 0.450 & 0.04 & 0.559 & 0.03 \\
\hline
\end{tabular}


Table 3b

Predicted Demand by Offer and Insurance Status

Thresholds for Any Insurance Predicted Demand

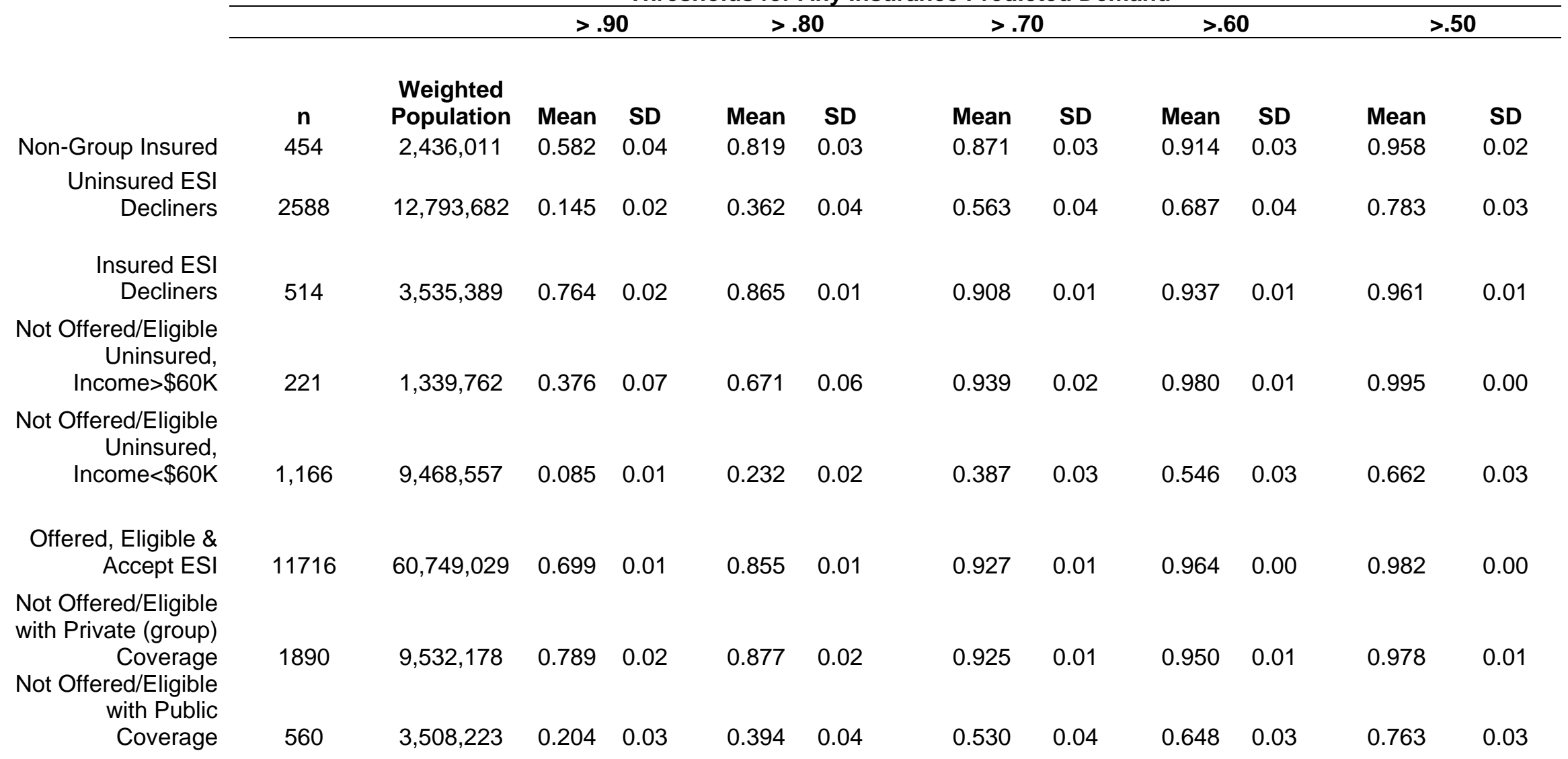


Figure 3

\section{Sorting in the Working Population, aged 18-64}

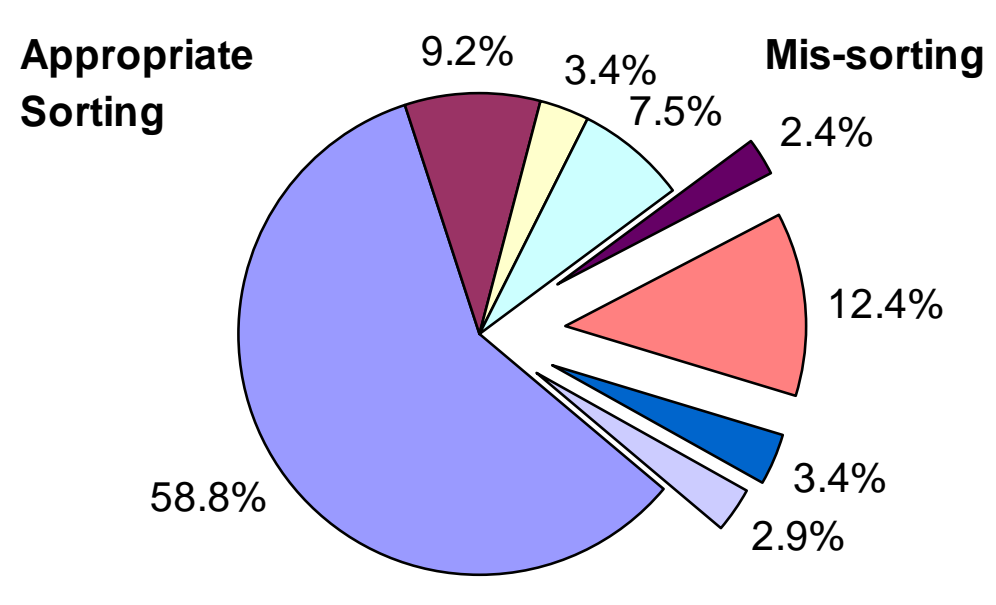

$\square$ Offered, Eligible and Accept

Not Offered/Eligible, Privately Covered

$\square$ Not Offered/Eligible, Publicly Covered

$\square$ Low Private Insurance

Demand, Uninsured

- Non-Group Covered

$\square$ Decline Offer, Insured

$\square$ Decline Offer, Uninsured

$\square$ High Private Insurance Demand, Uninsured 
Table 4

2003 Labor Market Match Status of the Working Population Aged 18-64

Labor Market Matches

Labor Market

Mismatches

$\begin{array}{rrr} & \text { Number } & \text { Percent } \\ & 82,322,076 & 79.6 \% \\ \text { Insured Matches } & 73,789,443 & 71.4 \% \\ \text { Offered, Eligible and Accept } & 60,749,034 & 58.8 \% \\ \text { Not Offered/Eligible, Privately Covered } & 9,532,182 & 9.2 \% \\ \text { Not Offered/Eligible, Publicly Covered } & 3,508,228 & 3.4 \% \\ & & \\ \text { Uninsured Matches } & 8,532,633 & 8.3 \% \\ \text { Uninsured } & 8,532,633 & 8.3 \% \\ & & \\ \text { Low Private Insurance Demand, } & & \\ \text { Insured Mismatches } & 15,229,697 & 14.7 \% \\ \text { Non-Group Covered } & 2,436,014 & 2.4 \% \\ \text { Decline Offer, Insured } & 12,793,683 & 12.4 \% \\ \text { Uninsured Mismatches } & 5,811,079 & 5.6 \% \\ \text { Decline Offer, Uninsured } & 3,535,391 & 3.4 \% \\ \text { Uninsured } & 2,275,688 & 2.2 \%\end{array}$

Total Weighted Population $103,362,831$ 


\begin{tabular}{|c|c|c|c|c|c|c|c|c|}
\hline & $\begin{array}{l}\text { Probability } \\
\text { Coefficient }\end{array}$ & & SE & Elasticity & $\begin{array}{l}\text { Probability } \\
\text { Coefficient }\end{array}$ & & SE & Elasticity \\
\hline 2002 Household Income, 000s & 0.0317 & $\star \star \star *$ & -0.0028 & 0.0077 & 0.0294 & $* \star *$ & 0.0026 & 0.0047 \\
\hline 2002 Household Income Sqrd, 000s & 0.0000 & $\star \star \star ~$ & 0.0000 & 0.0000 & 0.0000 & $\star \star \star *$ & 0.0000 & 0.0000 \\
\hline Income LE 1.5FPL & -0.5598 & 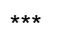 & -0.0946 & -0.1544 & -0.3543 & $\star \star \star *$ & 0.0787 & -0.0642 \\
\hline No. Adults in Family & -0.0063 & & -0.1592 & -0.0015 & -0.1634 & & -0.1474 & -0.0262 \\
\hline No. Adults in Family, Sqrd & 0.0159 & & -0.0399 & 0.0038 & 0.0566 & & -0.0400 & 0.0091 \\
\hline No. Children in Family & 0.0817 & & -0.0573 & 0.0197 & 0.1410 & $\star *$ & 0.0609 & 0.0226 \\
\hline No. Children, Sqrd & -0.0191 & & -0.0134 & -0.0046 & -0.0246 & & -0.0145 & -0.0039 \\
\hline Adult Child & 0.0619 & & -0.1035 & 0.0146 & 0.1490 & & -0.1231 & 0.0220 \\
\hline Other Adult in $\mathrm{HH}$ & -0.8649 & 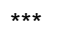 & -0.1070 & -0.2726 & -0.9031 & $\star * \star$ & 0.1078 & -0.2195 \\
\hline Non-Relative & 0.6314 & $\star \star \star$ & -0.1395 & 0.1098 & 0.6567 & $\star \star \star ~$ & 0.1396 & 0.0683 \\
\hline Married Spouse Present & -0.0752 & & -0.0702 & -0.0186 & -0.1445 & & 0.0734 & -0.0245 \\
\hline Has Non-Working Spouse & -0.2198 & $\star *$ & -0.1038 & -0.0583 & 0.0158 & & -0.1439 & 0.0025 \\
\hline Male $31-35$ yrs & 0.2648 & $\star \star \star ~$ & -0.0981 & 0.0562 & 0.1376 & & -0.0827 & 0.0202 \\
\hline Male $36-40$ yrs & 0.3597 & $\star \star \star ~$ & -0.1032 & 0.0729 & 0.1654 & & -0.0982 & 0.0239 \\
\hline Male $41-45$ yrs & 0.2814 & $\star \star$ & -0.1218 & 0.0594 & 0.1927 & & -0.1174 & 0.0274 \\
\hline Male $46-50$ yrs & 0.1470 & & -0.1032 & 0.0331 & 0.0685 & & -0.1177 & 0.0105 \\
\hline Male $51-55$ yrs & 0.4459 & $\star \star \star ~$ & -0.0964 & 0.0859 & 0.4808 & $\star * \star$ & 0.1311 & 0.0563 \\
\hline Male $56-60$ yrs & 0.7708 & $\star \star \star$ & -0.1263 & 0.1234 & 0.7896 & $\star \star *$ & 0.1513 & 0.0748 \\
\hline Male $61-64$ yrs & 0.6223 & 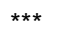 & -0.1690 & 0.1075 & 0.8092 & $* * *$ & 0.1514 & 0.0747 \\
\hline Female $31-35$ yrs & 0.2688 & $\star \star \star$ & -0.1016 & 0.0570 & 0.1635 & & -0.1061 & 0.0236 \\
\hline Female $36-40$ yrs & 0.2840 & $\star *$ & -0.1188 & 0.0598 & 0.1726 & & -0.1258 & 0.0248 \\
\hline Female $41-45$ yrs & 0.3965 & $\star \star \star$ & -0.1267 & 0.0790 & 0.3197 & $\star \star$ & 0.1367 & 0.0419 \\
\hline Female $46-50$ yrs & 0.4933 & $\star \star \star ~$ & -0.0969 & 0.0931 & 0.3426 & $\star \star \star *$ & 0.1053 & 0.0441 \\
\hline Female $51-55$ yrs & 0.6292 & $\star \star \star$ & -0.1402 & 0.1098 & 0.6502 & 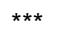 & 0.1724 & 0.0681 \\
\hline Female $56-60$ yrs & 0.7167 & $\star \star \star ~$ & -0.1480 & 0.1188 & 0.6130 & $\star * \star$ & 0.1852 & 0.0656 \\
\hline Female 61-64 yrs & 0.5405 & $\star \star \star *$ & -0.1508 & 0.0979 & 0.7391 & $\star \star \star *$ & 0.2409 & 0.0716 \\
\hline Excellent Health & 0.0854 & & -0.0547 & 0.0209 & 0.0446 & & -0.0645 & 0.0072 \\
\hline Fair Health & -0.1418 & & -0.1092 & -0.0362 & 0.1076 & & -0.0906 & 0.0162 \\
\hline $\begin{array}{l}\text { Poor Health } \\
\text { Family Member has Preference for }\end{array}$ & -0.1249 & & -0.2063 & -0.0319 & 0.0814 & & -0.1784 & 0.0124 \\
\hline Insurance & -0.1328 & & -0.0786 & -0.0332 & -0.1883 & $\star \star$ & 0.0776 & -0.0324 \\
\hline Risk Preference & 0.0744 & & -0.0583 & 0.0180 & 0.0620 & & -0.0646 & 0.0099 \\
\hline Black & 0.0761 & & -0.0706 & 0.0178 & 0.0995 & & -0.0786 & 0.0151 \\
\hline Hispanic Origin & -0.3487 & $\star \star \star$ & -0.0849 & -0.0944 & -0.3452 & $\star * \star$ & 0.0887 & -0.0648 \\
\hline Other Race & -0.2937 & $\star *$ & -0.1296 & -0.0802 & -0.1498 & & -0.1528 & -0.0262 \\
\hline Self: LT 9yrs Ed & -0.2959 & $* *$ & -0.1353 & -0.0813 & -0.3380 & $* \star \star$ & 0.1218 & -0.0664 \\
\hline Self: LT 12 Yrs Ed & -0.2247 & $\star \star \star$ & -0.0800 & -0.0595 & -0.2437 & $\star \star \star *$ & 0.0848 & -0.0447 \\
\hline Self: LT 16 Yrs Ed & 0.1111 & & -0.0597 & 0.0259 & 0.2036 & $* * *$ & 0.0753 & 0.0300 \\
\hline Self: College Ed or More & 0.4149 & $\star \star \star$ & -0.0653 & 0.0992 & 0.3965 & $\star \star \star *$ & 0.0860 & 0.0630 \\
\hline Constant & -0.2673 & & -0.1740 & & 0.1501 & & -0.1880 & \\
\hline Observations & 19109 & & & & 19109 & & & \\
\hline
\end{tabular}

